Danish Twin Register

Institute of Medical Genetics

University of Copenhagen
Psychiatric Research Dept.

University of Aarhus,

State Hospital, Risskov

\title{
The Danish Twin Register
}

\author{
M. Hauge, B. Harvald, M. Fischer, K. Gotlieb-Jensen \\ N. Juel-Nielsen, I. Raebild, R. Shapiro, T. Videbech
}

The potential value of twin studies and their applicability in a variety of fields within medical research have attracted increasing attention during the last Io-I5 years. This caused the World Health Organization to convene an international group of experts: geneticists, epidemiologists and clinicians, to review " the possible contribution of twin studies, a recognized tool in genetic research, to the broader field of epidemiological investigations". The report of the meeting, which was recently published in this journal (WHO Report, r966), discussed primarily the great importance of twin studies in epidemiology where the usual methods have been insufficient in as much as they do not permit an evaluation of the significance of the genetic constitution in the response to environmental influences affecting the health of an individual and a population. Great attention was paid to the methods of collection of twin materials and of the interpretation of the results obtained.

The fact that large series of twins are needed for this type of studies and that they should preferably be derived from whole populations or well-defined parts of a population will put rather serious limits to the general applicability of this approach and would emphasize the need for international collaboration. Parallel studies with the adoption of uniform methods would yield additional information of great value, not only in epidemiology, but also in genetic analyses of rare diseases and abnormalities. Large, unselected twin series of this type will improve the validity of classical twin studies which have often suffered from the bias introduced through the selection of the material. It is known that the generally adopted procedure of collecting twin materials from groups of patients or individuals with a given disease or trait will almost inevitably lead to the inclusion of an undue proportion of concordant and probably also of MZ pairs to an extent which is difficult to estimate (Luxenburger, I928; Simonds, 1957).

One of the first attempts to collect a complete twin population seems to have been made some twenty years ago by Essen-Möller in Scania, a province in the southern part of Sweden. This twin catalogue has been used in a number of studies, mostly related to the field of psychiatry (Essen-Möller, 1963). In 1954, the establishment of a twin registry covering the total Danish population was initiated (Harvald and Hauge, 
1956). In the following years projects have been launched in other countries, notably in Scandinavia and USA, where similar principles have been followed (Cederlöf et al, r96r; Kringlen, rg66; Jablon et al, r967).

The present communication intends to present and discuss one of the first studies of this extensive type, describing the methods which have been used and some of the results obtained in order to give a survey of the problems and difficulties encountered and the type of information which may be expected to appear in a twin series derived from a population of 2-2.5 million inhabitants with a frequency of twin births of about $1.35 \%$.

\section{Material and Methods}

The attempt to establish a twin register based on the complete Danish population was made in order to provide material for the study of the relative importance of genetic determinants in normal and abnormal characters. Such a material would comprise index twins derived from a twin population and not primarily selected because they presented the trait to be investigated. It was also hoped that the register could be used in some respects as a representative sample of the general population for the elucidation of a number of epidemiological problems. Finally, it was expected that some of the still unsolved problems specifically related to twins and twinning could find some clarification through this register.

\section{i.i. Collection of the Basic Material}

It was decided to initiate the registration by considering all births in the period 1870-1910 in order to obtain a sample of individuals who at the time of examination would have passed a major part of the risk period for a large number of diseases. The Danish population amounted to $\mathrm{I} .78$ millions in 1870 and 2.76 millions in I9I I. The frequency of twin births ranged from $\mathrm{I} .32$ to $1.39 \%$ of all births (still-births included) in the same period. All twins born were ascertained in the public birth registers, and it was intended to follow the individuals from birth until the time of registration or their death without paying any attention to the presence or absence of disease.

The official birth registers in Denmark are kept locally by the church authorities. Each of the parishes, numbering about 2000, runs a file of all births, marriages and deaths taking place withing the parish. The twin births were traced in each of these registers. It is the general rule that twin births are marked specifically, but in order to ensure complete ascertainment the clerks who searched the files were instructed to look for all cases where two children had been born on the same day. Even if it is compulsory to register all births it is clear that a few pairs may have been lost, but various checks have supported the view that registration of twin births may be considered virtually complete.

The first step in the follow-up of the twins was to make use of the register of deaths 
in the same parish. This would give the date of death of all those who died in the parish where they were born. In Copenhagen, a special register is available which includes all deaths which took place in the capital within the years I888-1936. Thus, twins born in Copenhagen and dying here would be traced even if they had moved from one parish to another as long as they did not leave the municipality of Copenhagen. As migration out of Copenhagen was much lower than from the country to towns and cities, including the capital, information about deaths has been more complete in pairs born in Copenhagen after I 888 than in other places.

The second step in the search was to ask the public registers, run by the municipalities, for any information they might have about the twins or their close relatives. Since I924, when these registers were established by law, it has been compulsory to report any change of address to the municipality. This implies that any person whose place of living in 1924 or later is known may at any moment be traced through these registers. Before I924, many towns and cities had annual censuses in addition to the nation-wide censuses carried through every five years. The reports of these detailed population surveys are still available and have been important sources of information. The same applies to the archives of the local probate courts where names and addresses of relatives of deceased persons may be found provided the day and place of death are known. Through these channels practically all twins have been traced if they stayed in the parish of birth until their death or until the public registers came into existence. Furthermore, even if the twins had moved it would in the majority of cases be possible to trace them if just one of the parents or sibs remained in the parish. On the other hand, twins belonging to families which moved with all its members while the twins were still young have been more difficult to locate.

A questionnaire was sent to the twins as soon as they were traced. If they were not alive at the time of registration it was attempted to locate their closest relative who then received the questionnaire. It was the intention to obtain the medical history by asking the informants to list all stays in hospitals and to indicate the prèsence or absence of symptoms of a number of specific diseases mentioned in the questionnaire. Some additional questions concerned the number of children of each individual, the number of twins among them, and the presence of left-handedness. In the case of twins belonging to same-sexed pairs specific questions were included about the degree of similarity between the partners which would permit an evaluation of the zygosity diagnosis as will be described below.

It was soon found impossible to get reliable information about medical events, including the cause of death, and especially about the zygosity diagnosis in twins dying at an early age. As same-sexed pairs of unknown zygosity are useless in most studies, it was at an early stage decided to stop the collection of information about a pair as soon as it was found that one partner had died before attaining the age of six years. Thus, the working material comprises in principle all twin pairs born in Denmark within the years 1870-1910 in which neither partner is known to have died prior to the day when he or she attained the age of six years.

In 1964, means were secured which allowed a gradual extension of the basic ma- 
terial by the inclusion of twin pairs from the following decade, 19II-I920. To ensure the most economic use of the funds it was decided to consider only same-sexed pairs as pairs with partners of different sex are of much lower value in nearly all studies. The collection of the primary data from this period is at the present moment still incomplete; about 30 parishes, all of them comparatively small, have not yet been able to furnish the basic data. The search for the twins follows the same lines as are described above.

\section{I.2. Determination of Zygosity}

The size of the material and the fact that one or both twins had in many cases died prior to the time of registration called for diagnostic methods other than the most reliable which are based on the extensive use of blood and serum group determinations. All questionnaires sent to same-sexed twins or their relatives comprised questions about the degree of similarity between the partners and about the difficulties, if any, experienced by parents, friends and other acquaintances in distinguishing between the two partners; on the basis of the answers all pairs were, on return of the questionnaires, classified as probably monozygotic (MZ), probably dizygotic (DZ) or of doubtful zygosity.

The class of MZ pairs includes all those pairs in which the partners were described as strikingly similar in appearance, i.e. more similar than ordinary sibs, and to such an extent that even people who knew the twins well found it difficult to distinguish one from the other.

The class of DZ pairs comprises such pairs where the partners were stated to present no striking similarity and where identity difficulties had never appeared.

Unclassifiable pairs constituted the remaining part of the same-sexed pairs. This group includes all pairs where no reliable information was available or where the informants disagreed about the similarity. Furthermore, pairs in which the partners claimed to be strikingly similar in appearance although they had never been mixed up would be placed in this class. The same applied to pairs denying any striking similarity but where it was stated that the partners had now and then been mistaken for one another. About $5 \%$ of the same-sexed pairs are found in this class.

This method of classification has been used in all cases, but it is the principle to include serological examinations in all same-sexed pairs with both partners being alive when more intensive studies are carried through. The serological approach has a higher degree of reliability which may be expressed numerically. This method allows a clear indication of the direction of misclassification and the order of magnitude of errors. In principle, any difference between two partners with regard to a well-defined serological character is taken as a proof of dizygosity. With the systems employed here it may be calculated that about $98 \%$ of all $\mathrm{DZ}$ twin pairs may be expected to show some serological difference proving their dizygosity (Dencker et al, ig6r). Thus, the class of serologically discordant pairs will include DZ twins only. The remaining same-sexed pairs with complete blood group concordance will comprise 
all $\mathrm{MZ}$ pairs plus a very small proportion of the $\mathrm{DZ}$ pairs. In a given series, the actual number of $\mathrm{DZ}$ pairs in the group of serologically concordant pairs may be estimated and the conclusions of the study may be considered in the light of this specified error of classification.

The validity of the zygosity classification based on answers to the questionnaires has been evaluated by a comparison with the results of later blood group determinations in 335 same-sexed pairs selected for special medical examinations which in some cases comprised MZ pairs only. The results of this comparison were as follows:

1) Pairs initially classified as MZ: I 70 out of 173 pairs in this class were subsequently found to be serologically concordant. The three remaining pairs presented one, two and three blood group discordances, respectively. Two of these three pairs were brought up apart which may have limited the value of their answers to the question about experiences of identity difficulties. The results give good reasons to believe that pairs in this class have an MZ probability of more than $95 \%$.

2) Pairs initially classified as DZ: I 43 out of I47 pairs in this class presented some blood group discordance proving their dizygosity. The remaining four pairs showing complete concordance with respect to the systems studied may or may not be DZ. This number of serologically concordant pairs in the DZ class is in agreement with the expected number according to the calculations mentioned above. Thus, the DZ probability of pairs placed in this class seems to exceed $95 \%$.

3) Unclassifiable pairs: The answers from 15 pairs contained some internal inconsistencies which made them unclassifiable: a) the partners from six pairs - all showing some blood group discordance - gave conflicting answers concerning their similarity; $b$ ) five pairs described themselves as strikingly similar in appearance, but they had on the other hand never experienced that they were mistaken for one another. Three of these five pairs were serologically discordant; $c$ ) four pairs stated that people who knew them had now and then found it difficult to distinguish between them in spite of the fact that they considered themselves clearly different in appearance; three of these pairs showed some blood group discordance.

The total results of this analysis indicate that the general reliability of the classification method used here is high with a frequency of misclassifications which is probably below $5 \%$. The group of unclassifiable pairs constitutes the most important problem, but the size of this group will be reduced in any more intensive study where an interview with the informants will provide more details regarding the similarity which will undoubtedly permit valid classification in an additional number of cases.

\section{I.3. The Present Composition of the Material}

The registration started, as mentioned in section I.I, from the total number of twin births in Denmark within the years 1870-1910. According to the official statistics $379^{1} 4$ pairs were born in this period. The search for the pairs continues until they have been traced. The collection of medical information starts with the questionnaires and continues with the perusal of case records from hospitals and general practition- 
ers as long as it may be expected that supplementary data of value will appear. The collection is, however, discontinued for reasons given above as soon as it is found that one partner of a pair has died before attaining the age of six years. The working material thus comprises two main parts:

Part $T$ : pairs about which complete or nearly complete medical information is

Tab. I. Composition of the Danish Twin Register

\begin{tabular}{|c|c|c|c|c|}
\hline \multirow{3}{*}{ Year of birth } & \multirow{3}{*}{$\begin{array}{c}\text { Total N. of } \\
\text { twin pairs } \\
\text { born }\end{array}$} & \multicolumn{3}{|c|}{ Total N. of pairs } \\
\hline & & \multicolumn{2}{|c|}{ Traced } & \multirow{2}{*}{$\begin{array}{l}\text { Untraced } \\
(\text { Part U })^{*}\end{array}$} \\
\hline & & $($ Part D)* & $\left.(\operatorname{Part} \mathrm{T})^{*}\right)$ & \\
\hline \multicolumn{5}{|c|}{ A. Total material } \\
\hline I $870-79$ & 7893 & $\begin{array}{c}5139 \\
(65.1 \%)\end{array}$ & $\begin{array}{c}1095 \\
(13.9 \%)\end{array}$ & $\begin{array}{c}1695 \\
(21.0 \%)\end{array}$ \\
\hline I $880-89$ & 8982 & $\begin{array}{c}5974 \\
(66.5 \%)\end{array}$ & $\begin{array}{c}1603 \\
(\text { I } 7.8 \%)\end{array}$ & $\begin{array}{c}1405 \\
(15.7 \%)\end{array}$ \\
\hline I 890-99 & $95^{20}$ & $\begin{array}{c}6207 \\
(65.2 \%)\end{array}$ & $\begin{array}{c}2073 \\
(2 \mathrm{I} .8 \%)\end{array}$ & $\begin{array}{c}1240 \\
(13.0 \%)\end{array}$ \\
\hline I900-09 & I039I & $\begin{array}{c}643^{8} \\
\left(62.0^{\circ}\right)\end{array}$ & $\begin{array}{c}2891 \\
(27.8 \%)\end{array}$ & $\begin{array}{c}1062 \\
(10.2 \%)\end{array}$ \\
\hline I9IO & 1128 & $\begin{array}{c}695 \\
(61.6 \%)\end{array}$ & $\begin{array}{c}339 \\
(30.1 \%)\end{array}$ & $\begin{array}{c}94 \\
(8.3 \%)\end{array}$ \\
\hline $\begin{array}{l}\text { Total } \\
\text { I } 870-\text { I9ıо }\end{array}$ & 37914 & $\begin{array}{c}24453 \\
(64.5 \%)\end{array}$ & $\begin{array}{c}8001 \\
(21.1 \%)\end{array}$ & $\begin{array}{c}5460 \\
(14.4 \%)\end{array}$ \\
\hline
\end{tabular}

B. Same-sexed pairs only (1891-1910)

\begin{tabular}{|c|c|c|c|c|}
\hline $1891-95$ & 3080 & $\begin{array}{c}2087 \\
(67.7 \%)\end{array}$ & $\begin{array}{c}609 \\
(19.8 \%)\end{array}$ & $\begin{array}{c}3^{8} 4 \\
(12.5 \%)\end{array}$ \\
\hline I8g6-ı 900 & 3065 & $\begin{array}{c}203 \mathrm{I} \\
(66.3 \%)\end{array}$ & $\begin{array}{c}73^{8} \\
(24 \cdot 1 \%)\end{array}$ & $\begin{array}{c}296 \\
(9.6 \%)\end{array}$ \\
\hline $1901-05$ & 3200 & $\begin{array}{c}2064 \\
(64.5 \%)\end{array}$ & $\begin{array}{c}829 \\
(25 \cdot 9 \%)\end{array}$ & $\begin{array}{c}307 \\
(9.6 \%)\end{array}$ \\
\hline 1906-10 & 3537 & $\begin{array}{c}2196 \\
(62.1 \%)\end{array}$ & $\begin{array}{c}1060 \\
(30.0 \%)\end{array}$ & $\begin{array}{c}28 \mathrm{r} \\
(7.9 \%)\end{array}$ \\
\hline $\begin{array}{c}\text { Total same-sexed pairs } \\
\text { 1891-1910 }\end{array}$ & 12882 & $\begin{array}{c}8378 \\
(65.0 \%)\end{array}$ & $\begin{array}{c}3236 \\
(25.1 \%)\end{array}$ & $\begin{array}{l}1268 \\
(9.9 \%)\end{array}$ \\
\hline
\end{tabular}

* Part D: pairs in which one or both partners are known to have died before attaining the age of six years. Part T: pairs in which both partners are known to have reached the age of six years. Part U: pairs which are not yet traced.

The percentages given are based on the total number of pairs born in the period. 
found in the Twin Register. All pairs in this group have remained unbroken at least until they attained the age of six years. Their present place of living or the place and time of their death is known. Contact has been established with the twins or their close relatives.

Part $U:$ pairs in this group are still untraced. Many of these pairs have undoubtedly been broken at an early age, but this fact has been difficult to verify in those cases where the twins moved from the parish in which they were born at an early age and without leaving a family member behind who lived long enough to enter the public registers when they came into existence.

Tab. I gives the details concerning the working material. It is evident that part $U$ includes a considerable proportion of the total number of twins born, but the proportion is constantly decreasing. A more detailed analysis has shown that female/ female pairs are more difficult to trace than male/male pairs, as would have been expected. The highest proportion of untraced pairs is, however, found among male/ female pairs, but this is caused by an early decision to spend less efforts on tracing this type of twins which for most purposes are of minor value. It may be mentioned that the proportion of untraced pairs among male/male pairs has been below $10 \%$ since 1895 , and it was only about $6 \%$ for pairs born in 1910 . The corresponding figure for female/female pairs has constantly been about $2 \%$ higher.

Part $\mathrm{T}$ and part $\mathrm{U}$ combined constitute the basis for the collection of a fully representative twin sample. 5 I I 6 pairs or $38 \%$ of the total are of different sex. The proportion of different-sexed pairs at birth was $36 \%$ in this period. The difference between the two figures is probably fully explained by the higher infant mortality in twins belonging to same-sexed pairs. Parts $\mathrm{T}+\mathrm{U}$ can be used as a basis for studies of diseases and abnormalities for which a central file of all known cases from the whole country or a geographically delimited region is in existence. If all data in the Twin Register are checked against such a file, a fully unbiased twin sample would be obtained. On the other hand, materials for the study of diseases which are not registered centrally can only be provided from part $\mathrm{T}$ of the Twin Register where the medical history of all the twins is available except for those who have refused cooperation; they make out less than $2 \%$ of part T. Thus, slightly less than 8000 pairs form the basis for such studies.

The latest addition to the Twin Register, comprising all same-sexed pairs born in the years I9II-1920, is as mentioned still incomplete. According to the official statistics, 7056 same-sexed pairs were born in this decade. More than 6500 of these have by now been ascertained in the birth registers, and it may be assumed that nearly all cases of early death in this group have been recognized as this is the first step in the search. On this basis it may be estimated that the percentage of pairs attaining the age of six years will be below 45 . 


\section{Results}

A short summary of the main results obtained in studies based on the Danish Twin Register will be given in the following. These studies have largely been of two types: I) periodical surveys based on the information found in the Register at a given time. The very first surveys gave only highly preliminary figures as the material has been growing constantly. It is attempted not only to find the untraced pairs but also to keep the Register up to date by an annual check of the data of the twins against the files of the Central Register of Death Certificates and through a biannual questionnaire sent to all surviving twins in same-sexed pairs;2) intensive studies of selected traits and abnormalities. The index cases for such investigations are taken from the Register at a given date, and the information available is supplemented by interviews, by clinical, laboratory and other examinations of all index twins and their partners as far as at all possible.

\section{I. Surveys}

The results of some of the surveys have been published previously (Harvald and Hauge, 1956, г958, г965; Hauge and Harvald, 196r). The findings have been summarized as uncorrected concordance figures as they appeared from the data of the Twin Register. The diseases included are those which occur with a relatively high frequency in the population: cardio-vascular disorders, bronchial asthma, tuberculosis, rheumatic fever, rheumatoid arthritis, epilepsy and the major psychoses. This last-mentioned group as well as malignant growths and diabetes mellitus, which were also included in the surveys, have been made the subjects of later special investigations. The main findings in the most recent survey of the Register are given in Tab. II. The results of a more detailed diabetes survey has been published separately (Harvald and Hauge, $1963 a$ ).

\subsection{Intensive Studies of Selegted Diseases and Abnormalities \\ 1. Somatic diseases}

The study of somatic diseases has in all cases been based on part $\mathbf{T}$ of the Twin Register. All twins exhibiting signs of a given disease according to the information found in the Register will serve as index cases or probands in the subsequent intensive investigation.

The first study of this type aimed at the elucidation of the relative importance of genetic factors in the etiology of malignant growths in general. The results showed that the diversity in the population with regard to the development of cancer in general is not to any significant extent determined by the genetic constitution (Hauge and Harvald, r 960 ; Harvald and Hauge, ${ }_{19} 6_{3} b$ ). The most significant findings are summarized in Tab. III. It ought to be stressed that these results do not exclude the existence of specific types of malignant growth with important genetic components 
Tab. II. Occurrence of selected somatic diseases in the Danish Twin Register based on a survey of 4368 same-sexed pairs

\begin{tabular}{|c|c|c|c|c|c|c|}
\hline \multirow[b]{2}{*}{ Disease } & \multicolumn{3}{|c|}{ MZ twins } & \multicolumn{3}{|c|}{ DZ same-sexed twins } \\
\hline & Concordant & Discordant & $\begin{array}{l}\text { Conc.rate } \\
\text { (proband } \\
\text { method) }\end{array}$ & Concordant & Discordant & $\begin{array}{l}\text { Conc.rate } \\
\text { (proband } \\
\text { method) }\end{array}$ \\
\hline Cerebral apoplexy & 44 & 76 & $0.3^{6}$ & 32 & 132 & 0.19 \\
\hline Coronary occlusion & $4^{\circ}$ & 82 & 0.33 & $4^{8}$ & I3I & 0.27 \\
\hline Tuberculosis & IOO & $8_{5}$ & 0.54 & 84 & 225 & 0.27 \\
\hline Rheumatic fever & 60 & I 18 & 0.33 & 24 & 214 & 0.10 \\
\hline Rheumatoid arthritis & $3^{2}$ & $3 \mathbf{I}$ & $0.5^{0}$ & 4 & 69 & 0.05 \\
\hline $\begin{array}{l}\text { Death from acute } \\
\text { infection }\end{array}$ & 20 & I I 7 & 0.14 & 28 & 207 & O. I I \\
\hline Bronchial asthma & 60 & 34 & 0.63 & $4^{8}$ & 77 & $0.3^{8}$ \\
\hline Epilepsy & 20 & I 7 & 0.54 & 12 & 37 & 0.24 \\
\hline
\end{tabular}

All numbers refer to individuals, not pairs.

Tab. III. Occurrence of cancer in the Danish Twin Register based on a material of 4368 same-sexed pairs

\begin{tabular}{|c|c|c|c|c|c|c|}
\hline \multirow[b]{2}{*}{$\begin{array}{l}\text { Site or type } \\
\text { of tumour in } \\
\text { proband }\end{array}$} & \multicolumn{3}{|c|}{ MZ twins } & \multicolumn{3}{|c|}{ DZ same-sexed twins } \\
\hline & $\begin{array}{l}\text { Concordant } \\
\text { Site of tumours } \\
\text { same diff. }\end{array}$ & $\begin{array}{c}\text { Dis- } \\
\text { cordant }\end{array}$ & $\left|\begin{array}{c}\text { Rate of } \\
\text { con- } \\
\text { cordance * }\end{array}\right|$ & $\begin{array}{l}\text { Concordant } \\
\text { Site of tumours } \\
\text { same diff. }\end{array}$ & $\begin{array}{l}\text { Dis- } \\
\text { cordant }\end{array}$ & $\begin{array}{c}\text { Rate of } \\
\text { con- } \\
\text { cordance }\end{array}$ \\
\hline
\end{tabular}

Leucosis, myeloma,

reticulosis

Sarcoma, melanoma

$\begin{array}{lll}0 & 1 & 1 \\ 0 & 0 & 8\end{array}$

8

o $3(+\mathrm{r})^{* *} \quad$ I3

Carcinomata :

\begin{tabular}{|c|c|c|c|c|c|c|c|c|}
\hline Stomach & 2 & $I(+I)$ & 26 & 0.13 & $o(+I)$ & 8 & 43 & o. I 7 \\
\hline Intestine & 2 & o & 26 & 0.07 & 2 & $5(+2)$ & $3^{8}$ & o.19 \\
\hline Lungs, pleura & o & $I(+I)$ & 8 & & o & o & 19 & \\
\hline Uterus & o & 0 & I4 & & 0 & 4 & $3^{2}$ & \\
\hline Breast & 4 & $2(+1)$ & I 7 & 0.29 & 6 & 3 & $3^{8}$ & 0.19 \\
\hline Skin & o & 3 & 2 & & 0 & I & 7 & \\
\hline Other sites & 0 & $I(+I)$ & $4^{I}$ & & o & $I O(+I)$ & $8_{7}$ & \\
\hline Total & 8 & $9(+4)$ & I 43 & 0.13 & $8(+r)$ & $35(+4)$ & 292 & 0.14 \\
\hline
\end{tabular}

Cancer diagnosis incom-

pletely verified

$6 \quad 6 \quad 3$ I

34

$5^{\circ}$

* Concordance rate calculated according to the proband method (cf Allen et al, 1967).

** Figures in brackets: cancer diagnosis in co-twin incompletely verified.

All numbers refer to individuals, not pairs. 
in the etiology, but the quantitative significance of such types must be low. As the material increases, studies of tumours of specific sites and types will become profitable. It is often discussed to which extent twins differ from the general population with respect to morbidity and mortality; it seems therefore worth mentioning that no significant discrepancies between the twin material and the general population were found with regard to the relative cancer mortality.

Peptic ulcer and diabetes mellitus are at present being studied intensively. The preliminary results of the investigation of peptic ulcers show that the rate of concordance is relatively low: $53 \%$ in $\mathrm{MZ}$ pairs ( 32 pairs) and $31 \%$ in same-sexed DZ twins (59 pairs) when concordance in the widest sense is considered, but the difference between the two rates is significant at the I\% level (Gotlieb-Jensen, r968). This seems to provide a strong support for the assumption of a specific genetic constitution as a basis for the development of peptic ulcer but environmental factors are, on the other hand, of almost equal importance with regard to appearance of clinical disease.

The findings in diabetes mellitus provide a different picture. Here, genetic factors seem to be of decisive importance as appears from Fig. I, where age-corrected con-

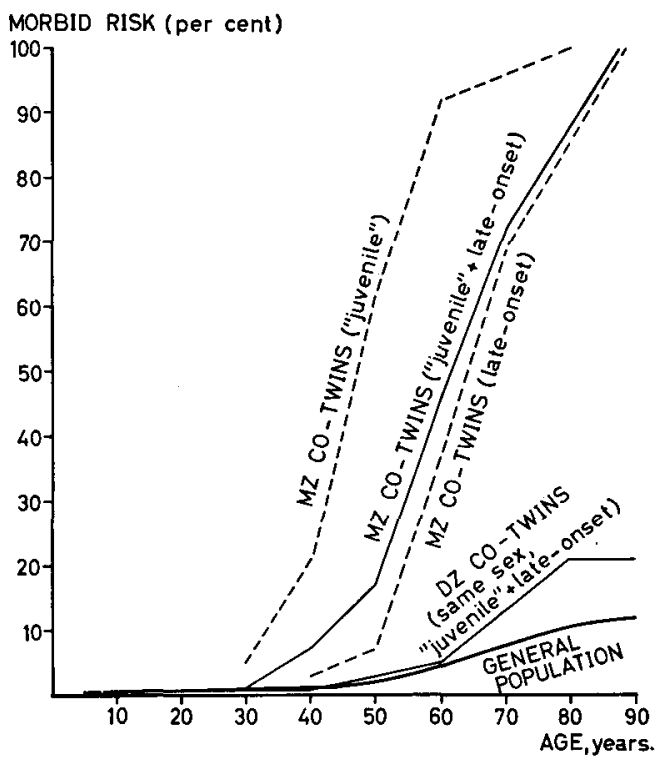

Fig. I. Morbid risk of co-twins of diabetic twin probands, calculated according to Nyholm and Helweg-Larsen (1954). "Juvenile" in this figure indicates diabetes in the twin proband diagnosed before the age of $5^{0}$ years. The risk for the general population has been calculated by Degnbol (1965).

cordance figures have been expressed as morbid risk or disease expectancy. The curves tend to show that concordance will be complete in $\mathrm{MZ}$ twins if they live long enough. The size of the peptic ulcer - and the diabetes - materials will permit more detailed analyses of the $\mathrm{MZ}$ pairs found to be discordant at the time of examination; this may throw light upon some of the eliciting environmental factors. 


\section{Psychic deviations and disorders}

It has in two connections been possible to come quite close to the ideal situation where the total twin material (parts $\mathrm{T}+\mathrm{U}$ ) can be utilized for the selection of index pairs. A central registration of law offenses, dating back before rgoo, has permitted the ascertainment of all criminals in the Twin Register. A central file of nearly all admissions to mental hospitals in Denmark since 1938 has made the collection of a representative series of twins with psychiatric disorders possible.

The criminological study, which is still under way, has been based on a sharply defined part of the Twin Register, viz. all twins born in the Danish islands between I 880 and I9Io. They have been matched against the Central Police Register and also the local penal registers to ensure complete ascertainment of law offenders. All twins entered here constitute the study material which at present comprises about I 000 pairs. No previous study of criminality in twins has been based on an unselected sample and the largest of the earlier investigations included a total of only 74 pairs. Some preliminary results have appeared recently (Christiansen, 1968); Tab. IV gives the most important figures which show - as expected - that concordance

Tab. IV. Occurrence of law offenders in the Danish Twin Register Preliminary results of an intensive study (Christiansen, 1968)

\begin{tabular}{|c|c|c|c|c|c|c|}
\hline & \multicolumn{3}{|c|}{ MZ twins } & \multicolumn{3}{|c|}{ DZ same-sexed twins } \\
\hline & Concordant & Discordant & $\begin{array}{l}\text { Conc.rate } \\
\text { (proband } \\
\text { method) }\end{array}$ & Concordant & Discordant & $\begin{array}{l}\text { Conc.rate } \\
\text { (proband } \\
\text { method) }\end{array}$ \\
\hline $\begin{array}{l}\delta \text { Twins } \\
\text { Crime + minor } \\
\text { offenses }\end{array}$ & $4^{8}$ & 43 & 0.53 & 28 & 100 & 0.22 \\
\hline $\begin{array}{l}\text { Minor offenses } \\
\text { only }\end{array}$ & & & 0.24 & & & 0.08 \\
\hline $\begin{array}{l}\text { Twins } \\
\text { Crime + minor } \\
\text { offenses }\end{array}$ & 6 & II & 0.35 & 2 & 22 & 0.07 \\
\hline $\begin{array}{l}\text { Minor offenses } \\
\text { only }\end{array}$ & & & 0 & & 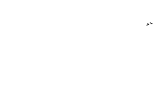 & \\
\hline
\end{tabular}

All numbers refer to individuals, not pairs.

even in the broadest sense is lower in this material than in all previous studies, but still with a highly significant difference between $M Z$ and DZ twins. Furthermore, it appears that concordance is much more pronounced with respect to crime than to minor offenses. The size of the material will permit detailed analyses of the asso- 
ciation of law offenses with place of birth as well as social class and other environmental variables.

The twins with psychiatric disorders, selected from the Twin Register, have been entered in the so-called Psychiatric Twin Register, the composition of which is outlined in Tab. V. Most of the groups are at present being studied intensively. The first results of the investigation of schizophrenic index pairs ( $16 \mathrm{MZ}$ pairs and 34 same-sexed DZ pairs) showed a similar tendency to lower $\mathrm{MZ}$ concordance rates

Tab. V. The Psychiatric Twin Register

Occurrence of psychiatric disorders in samesexed twin pairs born in 1870-1920

Distribution according to hospital diagnoses

\begin{tabular}{lr}
\hline \multicolumn{1}{c|}{ Diagnosis } & N. of p \\
\hline & \\
I. Schizophrenia & 70 \\
2. Manic-depressive psychoses & 68 \\
3. Paranoid psychoses & 16 \\
4. Psychotic and neurotic depressions & 67 \\
5. Neuroses, other than depressive & 2 I \\
6. Personality disorders & 50 \\
7. Patients with diagnoses I-6 who & \\
committed suicide (included above) & 22 \\
8. Suicides with unclassified psychiatric & \\
diagnosis & 55 \\
9. Other diagnoses & 48
\end{tabular}

Total 395

than in most older studies (Fischer, 1967). The full report will include a detailed clinical examination of the schizophrenic twins as well as their co-twins and close relatives.

All cases of suicide ascertained from the Death Certificates have been collected. This group includes $19 \mathrm{MZ}$ pairs four of which are concordant, and $5^{8} \mathrm{DZ}$ pairs, all discordant. They are at present being studied in detail, and a psychiatric evaluation of the index cases as well as their co-twins will soon appear (Juel-Nielsen and Videbech, to be published).

An intensive psychological-psychiatric study of those $M Z$ twins in the Register who were found to have been brought up apart was published by Juel-Nielsen (I965).

\subsection{Epidemiological Studies}

A specific inquiry into the smoking habits of the twins belonging to pairs with both partners being alive was made in 1959. The first analysis dealt with the influence of genetic factors on this character (Raaschou-Nielsen, I960), but this material was also used for a long-term study of the association between tobacco consumption and morbidity and mortality in general as well as with respect to diseases of the cardio- 
vascular and respiratory systems. This group is being followed continuously by periodic inquiries and annual matching with the Central Register of Death Certificates. The outcome of the 1966 survey appears from Tab. VI. Some of the diseases, notably in the cardio-vascular system, seem to have a higher frequency in those partners within each pair who have the higher tobacco consumption, but some more years

Tab. VI. Mortality and morbidity in relation to tobacco consumption

Material: 904 same-sexed pairs with both partners being

alive on January 1, 1959

Intra-pair comparison between heavier and lighter smoker

\begin{tabular}{c|c|c}
\hline \hline Year & \multicolumn{2}{|c}{ N. of deaths } \\
\cline { 2 - 3 } & $\begin{array}{c}\text { Heavier } \\
\text { smoker }\end{array}$ & $\begin{array}{c}\text { Lighter } \\
\text { smoker }\end{array}$ \\
\hline I959 & 5 & 4 \\
I960 & 6 & 4 \\
I961 & 4 & 4 \\
I962 & I3 & $\mathbf{5}$ \\
I963 & I0 & 8 \\
I964 & I4 & I3 \\
I965 & I4 & I0 \\
Total & 66 & 48 \\
\end{tabular}

Cause of death

Coronary occlusion

Cardiac insufficiency

Cancer of lung

Other types of cancer

Cerebral apoplexy

$\begin{array}{rr}27 & 13 \\ 5 & 6 \\ 3 & 2 \\ 16 & 1 \text { I } \\ 8 & \text { I } 2\end{array}$

Prevalence of

Angina pectoris

Non-fatal coronary occlusion

$29 \quad 25$

Claudication

$8 \quad 8$

Chronic bronchitis

23 I I

Peptic ulcer

$64 \quad 5^{6}$

$37 \quad 2 \mathrm{I}$

of observation will be needed before the differences may reach the level of statistical significance.

The relative importance of the genetic constitution in determining the life-span of an individual has been elucidated through an analysis of the mean intra-pair differences with regard to age at death in the pairs of part $T$ of the Twin Register (Hauge et al, 1964). The mean difference in MZ pairs was 14.5 years, a rather impressive 
figure which differs considerably from the general opinion on this point. The mean difference was significantly higher in same-sexed DZ pairs $(\mathrm{p}<\mathrm{r} \%)$; here it was found to be 18.6 years. It should be kept in mind that pairs in which one or both partners died before attaining the age of six years are disregarded in this analysis.

The results obtained in the study of peptic ulcer described above have been used

Tab. VII. Disease expectancy in peptic ulcer

Calculations based on a geographically

delimited section of the Danish Twin Register

\begin{tabular}{c|c|c}
\hline \hline $\mathbf{R}_{\times}{ }^{*}$ & $\delta$ & ? \\
\hline $\mathbf{R}_{45} \pm$ s.d. & $5.62 \pm 0.48 \%$ & $2.06 \pm 0.30 \%$ \\
$\mathbf{R}_{55} \pm$ s.d. & $6.93 \pm 0.54 \%$ & $2.86 \pm 0.36 \%$ \\
$\mathbf{R}_{65} \pm$ s.d. & $8.31 \pm 0.66 \%$ & $3.52 \pm 0.45 \%$ \\
$\mathbf{R}_{75} \pm$ s.d. & $9.24 \pm 0.82 \%$ & $\ldots$
\end{tabular}

* Risk of developing peptic ulcer before age $\mathbf{x}$ in individuals experiencing age $\mathbf{x}$.

(Calculations according to Nyholm and Helweg-Larsen, 1954).

in an attempt to estimate the morbid risk of the general population with respect to this disease. The figures are given in Tab. VII. A number of previous studies have provided prevalence figures, but no morbid risk estimates concerning this important disease have been available until now.

\section{Comments}

The practical difficulties involved in the establishment of a nation-wide twin register are clearly demonstrated by the present study. Unless the twins are examined at or shortly after birth and the zygosity is determined on the basis of an extensive series of serological characters, a very considerable part of a twin population is lost for most research purposes as a reliable zygosity diagnosis cannot be established retrospectively if one or both twins have died at an early age.

The main problem in the Danish Twin Register is connected with the difficulties of tracing those pairs which were born long before the national registration system was established and which left their parish of birth at an early age. A proportion of these pairs which have remained untraced has undoubtedly been broken in infancy and would, consequently, never be included in the working material. It is, on the other hand, clear that some of these pairs have survived infancy and should be included in all intensive studies. It would be important to have an estimate of the size of this latter group. The rate of stillbirths in twins may be evaluated with sufficient accuracy from the church registers. They show that the pair-wise rate of stillbirths (number of pairs with one or both partners stillborn divided by the total number 
of twin pairs born) was on the average six times higher than the rate of stillbirths in the general population in the period 1870-1910. The infant mortality rate in twins is unknown, but the file of deaths occurring in the municipality of Copenhagen permits an estimate of the pair-wise infant mortality rate of twins born here. This estimated value is lower than the true value because individuals born in Copenhagen but dying outside the capital will not be found in this special file, but as the infant mortality rate in the capital was higher than in other parts of the country, it may be assumed that the estimate based on the figures from Copenhagen may be not very far from the value which applies to the total Danish twin population. In the middle of the period under study the total pair-wise mortality below the age of six years was about $80 \%$ in the capital. Thus the proportion of surviving pairs would be about $20 \%$. As part $\mathrm{T}$ of the present material, i.e. pairs definitely known to have survived unbroken at least until they attained the age of six years, is $21 \%$ (cf Tab. I), there seems to be good reasons to believe that the majority of untraced pairs (part $\mathrm{U})$ have been broken or lost at an early age. Consequently, part T of the Twin Register may be assumed to comprise a very high proportion of all surviving pairs and thus constitutes a reliable basis for the ascertainment of index cases for intensive studies.

The most conspicuous difference between the group of traced pairs and the small group of surviving pairs still untraced seems to be that the latter includes a higher number of pairs which moved from their place of birth at an early age. Areas with a relatively low rate of emigration would, therefore, be expected to show a higher proportion of retrieved pairs. This is actually borne out by the finding that among pairs born in Copenhagen in the years $1896-1910$ only $3 \%$ of male/male pairs and $6 \%$ of female/female pairs have so far remained untraced, compared with 7 and ro $\%$, respectively, for the remaining part of the country. There seems to be no reason to expect an undue proportion of a specific zygosity type or with a specific disease among those pairs which moved from their place of birth at an early age as they would probably move in pairs at the decision of their parents. Twins moving at a higher age would be expected to leave some family member behind, and this would lead to the ultimate tracing of the twins.

It may be concluded that it is possible to obtain a representative twin sample by basing the selection of index cases on the material found in the Danish Twin Register. It may in some connections be preferable to restrict the selection to twins born in the more recent parts of the period or to analyse this group separately as it has been found more difficult to get useful medical information about individuals, not only twins, born prior to the years I 890-1895. Hospital records and death certificates from before Igro are rarely kept in the archives, and even if they are available they usually contain only very scanty information. Furthermore, the maximum loss of pairs born after I89o is very small (cf Tab. I). Even the more common diseases would be expected to be represented by no more than a few MZ pairs in this group. This gives good reasons to accept results obtained in studies based on the Twin Register as having a high degree of reliability. 


\section{Summary}

A description is given of the Danish Twin Register which is based on the total twin population born in Denmark in the years I870-I9Io with a more recent addition of all same-sexed pairs from the period IgII-I920. Twins belonging to pairs where one or both partners are found to have died before attaining the age of six years are disregarded in the more intensive studies whereas the remaining part of the twin population is being followed by periodical inquiries.

The methods used in the collection of the material, in the establishment of the zygosity diagnosis and in specific investigations of selected diseases and abnormalities are described and discussed.

A survey is given of the more important results of the research based on the Register. In the group of somatic diseases, greatest attention has so far been paid to malignant growths, diabetes mellitus and peptic ulcer. A number of psychiatric disorders and deviations are at present being studied with schizophrenia and criminality as the first subjects for intensive research. Some of the main results obtained are given as illustrations of the potentialities and scope of this approach to the application of twin studies in a broad variety of research areas.

\section{Acknowledgements}

The collection of the basic data of the Twin Register and the studies on malignant growths have been supported by research grants C- $94^{8}$ and GM $094^{1} 8$ from the National Institutes of Health, Public Health Service, U.S. Department of Health, Education and Welfare, Bethesda, Md. The extension of the Twin Register beyond 1910 has been made possible by grants from Statens Almindelige Videnskabsfond, Fonden til Laegevidenskabens Fremme and F. L. Smidth \& Go. A/S's Jubilaeumsfond, to the two senior authors.

The study of diabetes in the twins is aided by a grant from Landsforeningen for Sukkersyge to the two senior authors and Dr. Ingrid Raebild.

The epidemiological studies related to tobacco consumption are being conducted in collaboration with Professor D. Reid, Department of Epidemiology and Medical Statistics, London School of Hygiene and Tropical Medicine, London, England.

\section{References}

Allen G., Harvald B., Shields J. (1967). Measures of twin concordance. Acta Genet. (Basel), 17: 475$48 \mathrm{r}$.

Cederlöf R., Friberg L., Jonsson E., Kaij L. (I96I). Studies on similarity diagnosis in twins with the aid of mailed questionnaires. Acta Genet. (Basel), 11: $338-362$.

Guristiansen K. O. ( 1968 ). Threshold of tolerance in various population groups - illustrated by results from a Danish criminological twin study. In: The Abnormal Offender. Report of a Ciba Foundation Symposium, London.

Degnbol B. (1965). Prize essay on the genetics of diabetes mellitus. University of Copenhagen. (Unpubl.).

Dencker S. J., Hauge M., Kaij L., Nielsen A. (196i). The use of anthropological traits and blood groups in the determination of the zygosity of twins. Acta Genet. (Basel), 11: 265-285. 
Essen-Möller E. (1963). Twin research and psychiatry. Acta Psychiat. Scand., 39: 65-77.

Fischer M. (1967). Danish twin studies in schizophrenia. In Schields J.: Summary of the genetic evidence. Paper read at the Conference on the Transmission of Schizophrenia. Puerto Rico, June 26 - July, I, 1967. Gotlieb-Jensen K. (Ig68). Peptic ulcer in twins. (In press).

Harvald B., Hauge M. (1956). A catamnestic investigation of Danish twins. Dan. Med. Bull., 3: 150-158. - - (1958). A catamnestic investigation of Danish twins. Acta Genet. (Basel), 8: 287-294.

- - ( $\left(9^{6} 6_{3}\right)$. Selection in diabetes in modern society. Acta Med. Scand., 173: $459-465$.

- $(1963 b)$. Heredity of cancer elucidated by a study of unselected twins. J.A.M.A., 186: $749-753$.

- - (1965). Hereditary factors elucidated by twin studies. In Neel J. V., Shaw M., Schull W. J.: Genetics and the Epidemiology of Chronic Diseases. U.S. Department of Health, Education and Welfare, Washington.

Hauge M., Harvald B. (Ig60). Studies in the etiology of intracranial tumours. Acta Psychiat. Scand., 35: $163-170$.

- - (1961). Malignant growths in twins. Acta Genet. (Basel), 11: $372-37^{8}$.

- Degnbol B. (1964). Hereditary factors in longevity. In Hansen P.: Age with a future. Proceed. Sixth Intern. Congr. Geront., Munksgaard, Copenhagen.

Jablon S., Neel J. V., Gershowitz H., Atkinson G. F. (1967). The NAS-NRG twin panel: methods of construction of the panel, zygosity diagnosis and proposed use. Amer. J. Hum. Genet., 19: I33-16r.

Juel-Nielsen N. (1965). Individual and environment. Acta Psychiat. Scand., Suppl. 183.

Kringlen E. (Ig66). Schizophrenia in twins. Psychiatry, 29: 172-184.

LuXenburger H. (I928). Vorläufiger Bericht über psychiatrische Serienuntersuchungen an Zwillingen. Z. Ges. Neurol. Psychiat., 116: $297-326$.

Nyholm M., Helweg-Larsen H. F. (1954). On the computation of morbid risk. Acta Genet. (Basel), 5: $25-3^{8 .}$

RaAschou-Nielsen E. (1960). Smoking habits in twins. Dan. Med. Bull., 7: 82-88.

Simonds B. (1957). The collection of 300 twin index cases for a study of tuberculosis in twins and their families. Acta Genet. (Basel), 7: 42-47.

W.H.O. Report (1966). The use of twins in epidemiological studies. A.Ge.Me.Ge., 15: 109-128.

Dr. M. Hauge. Institute of Medical Genetics, University of Copenhagen, Denmark. 


\section{RIASSUNTO}

Viene descrittto il registro gemellare danese basato sull'intera popolazione gemellare nata in Danimarca dal 1870 al 1910, con un'aggiunta più recente di tutte le coppie dello stesso sesso per il periodo 1911-1920. I gemelli appartenenti a coppie in cui uno o ambedue $i$ membri risultino essere morti prima di aver raggiunto l'età di 6 anni, non vengóno presi in considerazione negli studi più approfonditi, mentre la parte restante della popolazione gemellare viene seguita mediante inchieste periodiche.

Vengono descritti e discussi i metodi adottati nella raccolta del materiale, nella diagnosi di zigotismo ed in ricerche epidemiologiche specifiche.

Vengono passati in rassegna $i$ principali risultati delle ricerche basate sul registro gemellare. Nel gruppo delle malattie somatiche sono stati studiati principalmente tumori maligni, diabete mellito e ulcera peptica. Attualmente sono in corso di studio alcune alterazioni e deviazioni psichiatriche, insieme alla schizofrenia e alla criminalità. Alcuni dei principali risultati ottenuti vengono indicati per illustrare le possibilità potenziali di questo tipo di studi gemellari in un vasto campo di ricerche.

\section{RESUME}

Les Auteurs décrivent le Registre Gémellaire Danois, basé sur toutes les naissances gémellaires en Danemark de 1870 à 1910 et les couples du même sexe de 1911 à 1920. Les jumeaux membres de couples avec un ou deux partenaires n'ayant pas atteint l'âge de 6 ans, ne sont pas considérés dans les études plus étendues, tandis que les autres sont fait l'objet d'enquêtes périodiques.

Les méthodes adoptées dans le rassemblement du matériel, le diagnostic de zygotisme et les recherches épidémiologiques spécifiques sont décrites et discutées.

Les principaux résultats des recherches basées sur le Registre sont aussi examinés. Dans le groupe des maladies somatiques ont été surtout étudiés tumeurs, diabète et ulcère peptique. Quelques altérations et déviations psychiatriques, ainsi que la schizophrénie et la criminalité, sont à présent en cours d'étude. Quelques-uns des principaux résultats obtenus sont indiqués afin d'illustrer les possibilités potentielles de ce type d'études gémellaires dans de très vastes secteurs de recherche.

\section{ZUSAMMENFASSUNG}

Beschreibung des dänischen Zwillingsregistars. Dieses enthält die gesamte zwischen 1870 und 1910 in Dänemark geborene Zwillingsbevölkerung mit einem neueren Zusatz aller gleichgeschlechtlichen Zwillingspaare der Zeit von 1911 bis 1920 . Bei den gründlicheren Untersuchungen werden die Zwillinge, von denen ein Paarling oder beide vor Vollendung des sechsten Lebensjahres verstarben, nicht berücksicht: die übrige Zwillingsbevölkerung wird hingegen periodisch Untersuchungen unterzogen.

Verf. beschreiben und erörtern die bei Zusammenstellung des Materials, bei der Eiigkeitsdiagnose und bei den spefizischen epidemiologischen Forschungen angewandten Methoden.

Úbersicht über die wichtigsten Ergebnisse de: auf das Zwillingsregister gestützten Untersuchungen. Unter den somatischen Leiden wurden hauptsächlich bösartige Geschwülste, Diabetes mellitus und Ulcus pepticum studiert. Zur Zeit sind Forschungen über einige psychiatrische Veränderungen und Abweichungen sowie über Schizophrenie und Kriminalität im Gange. Es werden einige der wichtigsten Ergebnisse angeführt, um zu zeigen, dass diese Art Zwillingsforschungen potentielle Möglichkeit für ein weites Studiengebiet liefert. 